Artículo Original

Recibido para publicación: 20 Octubre de 2015 Aceptado para publicación: 27 Noviembrede 2015

\title{
CLAUSULA DE LOS DERECHOS HUMANOS EN LOS TRATADOS DE LIBRE COMERCIO SUSCRITOS POR COLOMBIA
}

\section{Human rights clause in free trade agreements signed by Colombia}

\author{
Autores: Indira Alexandra Ricaurte Villalobos ${ }^{1}$ \\ (Estudiantes asistentes). \\ Roberto Carlos Cumplido Campo \\ Alejandro Andres Huerta Quintero \\ Luis Eduardo Lopez Del Rio \\ Moises Morales Hernandez \\ Correspondencia: Indira.ricaurte@curnvirtual.edu.co
}

\section{RESUMEN:}

El presente artículo de reflexión tiene como objeto sustentar teóricamente como el Sistema Interamericano ha ejercido una influencia en el rol de las autoridades colombianas cuando éstas han tenido que ejecutar las decisiones que emanan de la Comisión y de la Corte Interamericana, aclarando que éste no es el objeto del presente estudio. Así las cosas, nuestro sistema de fuentes no solamente ha tenido que responder a la tradicional discusión que suscita el artículo 230 de la Constitución Política en relación con el carácter auxiliar o principal de la jurisprudencia (López, 2006), sino que se ha visto enfrentado al dilema acerca de si las decisiones de la Comisión y la jurisprudencia interamericana tienen un valor vinculante en el sistema de fuentes colombiano.

\section{Palabras Claves}

Cláusula de los derechos humanos, tratados de libre comercio, Sistema interamericano de Protección de Derechos Humanos.

\begin{abstract}
This article aims at reflecting theoretically support as the Inter has influenced the role of the Colombian authorities when they have had to implement the decisions emanating from the Commission and the Court, noting that this is not the object of this study. So, our system of sources not only has had to respond to the traditional discussion raised by article 230 of the Constitution in relation to the auxiliary or main character of jurisprudence (Lopez, 2006), but has been faced the dilemma about whether the decisions of the Commission and the Inter-American jurisprudence have a binding value system Colombian sources.
\end{abstract}

\section{Keywords:}

Human Rights Clause, Free Trade Agreements, the Inter-American System of Human Rights Protection

\footnotetext{
${ }^{1}$ Abogada de la universidad de Cartagena, Docente - investigadora de la corporación universitaria Rafael Núñez de Cartagena.
} 


\section{INTRODUCCIÓN}

Parece indudable que el comercio, tanto de bienes como de servicios, es una fuente fundamental de progreso y desarrollo para los seres humanos y todo tipo de comunidades humanas; y que esa afirmación puede hacerse también extensible al comercio internacional respecto de las Naciones.De ahí a sostener la aspiración a la máxima libertad del comercio internacional hay solo un pequeño paso, que las grandes potencias económicas mundiales han dado después de siglos de proteccionismo y respecto de aquellos productos, principalmente manufacturados 0 industriales, en que son competitivos. Como ha señalado la doctrina especializada "el comercio en las relaciones económicas internacionales es un área de interés clave para los Estados desarrollado. Pero esta prioridad está sesgada políticamente. Para la mayoría de Estados, incluyendo los países en desarrollo, el desarrollo tiene sin duda mucha más importancia" , y ese desarrollo, sobre todo si lo cualificamos con adjetivos como "humano" y "sostenible", requiere de una fuerte agenda social amén de políticas económicas diseñadas a tal fin que pueden ser incompatibles con la entrada irrestricta de productos provenientes de estados notablemente más avanzados. Así pues, comercio sí y acuerdos comerciales, también; pero no de cualquier manera. Tras el desastre económico y político que supuso el proteccionismo de los años 20 y 30 del siglo pasado, el sistema multilateral del comercio ha tendido, bajo el paraguas institucional primero del GATT (1947) y actualmente de la OMC (1995), a la liberalización del comercio internacional.

Pese a las críticas que este sistema pueda merecer, en los términos que señalábamos en el párrafo anterior, lo cierto es que se le debe reconocer como mínimo dos virtudes desde el punto de vista de los países en vías de desarrollo. En primer lugar, la incorporación de un régimen específico para estos países. 
Vol.7, No 1. Diciembre de 2015 pp. $161-172$

Dicho régimen tiene dos hitos principales: la adición de la Parte IV del GATT (1964), que dio lugar al principio de no reciprocidad con los países desarrollados y que supone una enmienda a la totalidad a la lógica general del sistema (cláusula de la nación más favorecida); y, para hacer efectivo ese principio, la cláusula de habilitación (1979), que permite la posibilidad de conceder preferencias comerciales a estos países y que se ha concretado en el llamado "Sistema Generalizado de Preferencias".

En segundo lugar, el carácter multilateral del sistema ha dotado de mayor legitimidad a sus sucesivas ampliaciones, a través del sistema de "rondas" negociadoras: no es que éstas carezcan de sesgos de poder, pero sin duda favorecen alianzas estratégicas entre países más débiles o entre estos y alguna potencia, que equilibran los intereses estrictamente de parte de las grandes potencias comerciales.

Ahora bien, Una de las barreras casi infranqueables que han sufrido las propuestas de los Tratados de Libre Comercio (el de USA, el de Canadá y el de la Unión Europea), ha sido el fuerte cuestionamiento al gobierno colombiano por los altísimos niveles de violaciones a los derechos humanos y derechos sindicales. Muy poco puede argumentar el gobierno colombiano para refutar estas acusaciones.

Al mismo tiempo, basta hacer referencia al artículo 103 de la Carta de las Naciones Unidas, que dice que "en caso de conflicto entre las obligaciones contraídas por los Miembros de las Naciones Unidas en virtud de la presente Carta y sus obligaciones contraídas en virtud de cualquier otro convenio internacional, prevalecerán las obligaciones impuestas por la presente Carta".

Esto implica que en el contexto de los compromisos que han asumido los Estados en materia comercial y de inversión, su responsabilidad principal es la de 
promover y proteger los derechos humanos por encima de los derechos mercantiles.

Desde la época de los 90 se ha venido implementando, usando la figura de la 'condicionalidad política', que ha sido entendida como una herramienta para la promoción de la democracia y los derechos humanos. Se puede decir que desde esa época para acá, este condicionamiento ha sido incluido en cada acuerdo económico, de asociación o de cooperación, firmado por la Unión Europea, con terceros países.

El Acuerdo entre Colombia y La Unión Europea incluye la cláusula democrática pero no se sale del texto 'estándar' de las cláusulas tradicionalmente firmadas en los acuerdos comerciales.

Las organizaciones que han hecho seguimiento a las negociaciones han denunciado, que la cláusula democrática incluida en el acuerdo con Colombia, es un abierto retroceso a lo poco avanzado en materia de derechos humanos por la misma Unión Europea. No existe en esta cláusula, mención a los principios generales que reconocen que el objetivo del Acuerdo que es promover el desarrollo sostenible (económico y social) y la distribución justa de los beneficios, principios estos que por lo menos son mencionados en otros Acuerdos, como el de Chile o México, por ejemplo.

En adición a lo anterior, en esta cláusula tampoco aparecen figuras básicas de democratización, como por ejemplo, no hay una mención expresa a la participación de la sociedad civil, no hay un pilar real en materia socio laboral, tan solo vagas menciones o contenidos básicos, no incorpora el tratamiento del cambio climático, no hay previsión de análisis sobre los impactos antes, durante y después del Acuerdo, en temas tan sensibles como los aspectos económicos / comerciales, socio laborales y medioambientales; y para rematar, no considera el 
tema migratorio, asunto de vital importancia, tanto para Colombia, como para la Unión Europea.

Estos acuerdos comerciales perjudicarán a la mayoría de la población, a través de la profundización de políticas económicas que han llevado a la crisis actual y beneficiará a una élite reducida de empresarios nacionales y a las grandes empresas europeas que tienen inversiones en el país. Tampoco es cierto que habrá nuevas exportaciones colombianas, pues el $85 \%$ de lo que compra el bloque europeo, son productos primarios, comercio que ya tienen controlados las multinacionales de tiempo atrás.

Dicho lo anterior, se concluye que la cláusula democrática contenida en estos acuerdos comerciales, está muy lejos de representar una posibilidad de protección efectiva de los derechos económicos, sociales, culturales, laborales, étnicos, ambientales, de género, de la población colombiana, por carecer de los mecanismos concretos para garantizar su preservación y promoción. Ni siquiera es posible una real participación y supervisión de los órganos legislativos nacionales y de la sociedad civil, pues toda la mecánica de los tratados queda en manos de los gobiernos y del mercado.

\section{MÉTODOS}

Esta artículo se deriva de una investigación de tipo descriptiva, ya que nos hemos basado en la lectura y análisis de diversos textos que manejan el tema en estudio, por tal razón esta se encuentra soportada en las diferentes concepciones y teorías que se han trabajado a través del tiempo, las cuales constituyen nuestras fuentes primarias; igualmente hemos estado trabajando con teorías actuales, jurisprudencias, entre otros; con las cuales se hace mucho más fácil el manejo de 
información para nuestro trabajo, y con lo cual esperamos óptimos resultados para nuestro estudio de derecho.

La recopilación de datos e información que hemos obtenido hasta el momento parten de aquellas teorías de algunos autores que trataron el tema de nuestro trabajo, y de algunas jurisprudencias. Las fuentes secundarias que nos sirvieron de apoyo y ayuda para la obtención de información la tuvimos en la biblioteca miguel enrique Castañeda CURN, en la biblioteca Bartolomé calvo, y en algunos sitios en internet que nos condujeron a ampliar nuestra base se información.

Para efectos de la construcción de nuestro trabajo, planteamos primeramente un rastreo bibliográfico para la recolección de información y la cual nos permitió tener citas bibliográficas que nos ubicaran en el tema y con el cual formularnos y planteamos el problema a resolver, de igual modo sentamos bases para el enfoque en el cual se enmarca nuestra investigación.

En esta segunda etapa de la investigación ampliamos mucho más los conceptos obtenidos de una forma más concisa nuestro tema y ampliamos los conceptos y definiciones que obtuvimos con el rastreo; igualmente analizamos los antecedentes históricos y normativos de nuestro tema planteado. Al analizar y estudiar los diferentes conceptos obtenidos previamente en nuestra investigación, trataremos de llegar a una conclusión y poder de este modo dar respuesta a nuestras incógnitas planteadas al inicio del trabajo investigativo. Ahora bien en la tercera parte de este trabajo de investigación trataremos de dar respuesta a las incógnitas planteadas al inicio del trabajo, puesto que será en torno a todo este análisis que encontraremos los resultados que queremos obtener para nuestro estudio. 


\section{RESULTADOS Y DISCUSIÓN}

Para concluir, cabe destacar que En el caso colombiano, tenemos que el artículo $4^{\circ}$ de la Constitución establece que la Constitución es norma de normas y que ante cualquier incompatibilidad entre la Carta Política y otra norma jurídica, se aplicarán las disposiciones constitucionales. Esta disposición refleja claramente un monismo con supremacía de la Constitución. Sin embargo, el artículo 93 establece que los tratados de derechos humanos que prohíben su limitación en los estados de excepción prevalecen en el orden interno, situación que refleja una posición monista internacionalista y por ende una contradicción en la interpretación de ambas disposiciones constitucionales. Para López y Sánchez, citado por celemín(2012), la primera dificultad al intentar armonizar las normas internas con las normas internacionales de derechos humanos fue el problema hermenéutico del artículo $4^{\circ}$ y 93 de la Constitución. Sobre el particular, la Corte Constitucional por medio de la sentencia C-400 de 1998 señaló que en el orden interno colombiano hay una clara prevalencia de la Constitución sobre los tratados internacionales. Sin embargo, esto no implica la invalidación automática de la norma internacional, postura que identificó como un monismo moderado constitucionalista.

En dicha jurisprudencia la Corte entendió que ni siquiera los tratados de derechos humanos a los que se refiere el artículo 93 tienen jerarquía supra constitucional, toda vez que con la incorporación del denominado bloque de consitucionalidad estos tratados entran a ser parte integrante de la Carta Política.

El problema hermenéutico entre la supremacía de la Constitución y la jerarquía de los tratados internacionales de derechos humanos fue resuelto por la Corte Constitucional Colombiana con la incorporación del llamado Bloque de Constitucionalidad.2 Así las cosas, dice el profesor Alejando Ramelli: las contradicciones existentes en la Carta Política entre los principios de supremacía 
Vol.7, No 1. Diciembre de 2015 pp. 161 -172

constitucional y prevalencia de determinados tratados internacionales sobre derechos humanos y derecho internacional humanitario, la Corte Constitucional recurrió, de una manera muy particular, a la técnica francesa del "bloque de constitucionalidad", con el fin de solventar las mencionadas antinomias jurídicas.

Con el término bloque de constitucionalidad se ha querido expresar la idea según la cual existen normas que no aparecen en el texto constitucional, pero son relevantes para el control constitucional. La jurisprudencia de la Corte Constitucional ha establecido diferentes elementos que permiten identificar si una norma internacional hace parte del bloque de constitucionalidad.

En este sentido, la sentencia C-225 de 1995 que marca el punto de partida de la técnica francesa, establece los siguientes elementos: i) Que se trate de un tratado que consagre un derecho humano. ii) Que dicho tratado prohíba la limitación de ese derecho humano durante los estados de excepción. En este orden de ideas, el artículo 27 de la Convención Americana sobre Derechos Humanos enuncia aquellas normas internacionales que reúnen los parámetros trazados por la jurisprudencia constitucional. Así las cosas, dicha disposición convencional establece que durante los estados de excepción no podrán ser suspendidos los siguientes derechos:

a) "Derecho al reconocimiento de la personalidad juridica (Art. $3^{\circ}$ )

b) Derecho a la vida (Art. $4^{\circ}$ )

C) Derecho a la integridad personal (Art. 5ํㅜ)

d) Prohibición de la esclavitud y servidumbre (Art. 6을

e) Principio de legalidad y de retroactividad (Art. 9$)$

f) Libertad de conciencia y de religion (Art. 12)

g) Protección a la familia (Art. 17)

h) Derecho al nombre (Art. 18)

i) Derechos del niño (Art. 19)

j) Derecho a la nacionalidad (Art. 20)

k) Derechos Políticos (Art. 23) 
I) $\mathrm{Ni}$ las garantías judiciales indispensables para la protección de dichos derechos." Igualmente otros instrumentos internacionales de derechos humanos como el Pacto Internacional de Derechos Civiles y Políticos (1966), cuyo artículo 4.2 enuncia, al igual que lo hace la Convención Americana, algunos derechos que no pueden suspenderse durante situaciones de anormalidad; la Convención sobre los Derechos del Niño tampoco permite la derogación de sus clausulas; y aquellos tratados internacionales adoptados en el ámbito universal y regional que prohíben actos como la tortura, la desaparición forzada de personas y el genocidio.

Años más tarde, la Corte Constitucional por medio de la sentencia C-191 de 1998 introdujo una distinción del bloque de constitucionalidad en stricto sensu y lato sensu. El bloque en stricto sensu integra aquellas normas que tienen por mandato de la propia Carta Política rango constitucional, esto es, aquellas normas internacionales que reconocen los derechos humanos y prohíben su limitación en los estados de excepción. Mientras que el bloque lato sensu comprende las siguientes normas: que tienen un rango normativo superior a las leyes ordinarias y cuya función es servir de referente necesario para la creación legal y para el control constitucional y estaría conformado por el articulado de la Constitución (incluido el preámbulo), las leyes estatutarias, las leyes orgánicas, algunos tratados y convenios de internacionales sobre derechos humanos que admiten ser limitados bajo estados de excepción, y los instrumentos internacionales sobre límites.( Sierra Garcia, 2001)

En definitiva, el sistema jurídico colombiano no le otorga una jerarquía supra constitucional a los tratados internacionales de derechos humanos que prohíben su limitación en estados de excepción, sino que en virtud de la figura del bloque de constitucionalidad los integra a la Carta Política para que gocen de un rango constitucional. Contrario sensu, aquellos tratados de derechos humanos cuya suspensión es admisible en situaciones de anormalidad o aquellas otras normas que se ubican en el bloque lato sensu, no tienen rango constitucional pero si constituyen parámetros de interpretación para el control de constitucionalidad. 


\section{CONCLUSIONES}

La Carta de la ONU establece la primacía del Derecho Internacional de los derechos humanos sobre cualquier otro tipo de obligación internacional . Primacía que debe respetarse durante cualquier negociación y celebración de tratados internacionales ligados al comercio internacional. En particular cuando, como ocurre con frecuencia, el énfasis de estos es promover y proteger los "derechos" de las empresas y los inversionistas, en contraste con el enfoque de los tratados de derechos humanos que protegen los derechos de todas las personas por igual y, además, prevén una protección especial a los sectores vulnerables y mecanismos internacionales para asegurar su efectividad. Aunque los defensores de los Tratados de Libre Comercio - TLC y acuerdos comerciales similares sostienen que de ellos deriva un mayor nivel de bienestar humano generado por la expansión del comercio internacional; la realidad demuestra que ni el mercado ni la competencia garantizan, por sí mismos, la vigencia de los derechos humanos. (Naranjo Mesa, 2013)

El bienestar de la gente depende esencialmente de la capacidad estatal para garantizar y responsabilizarse por la vigencia de estos derechos, lo que implica que su responsabilidad principal es promover y proteger los derechos humanos y no los derechos de las empresas. Desde 1992, la Unión Europea ha suscrito más de 120 acuerdos comerciales y de cooperación con terceros países donde ha incorporado, como el primero de sus artículos, una Cláusula Democrática2 en la que las partes declaran que los derechos humanos constituyen un elemento esencial de las relaciones comerciales, lo que representa un avance en línea con los propósitos de la Organización de las Naciones Unidas y las recomendaciones formuladas por los órganos encargados de la promoción y protección de los derechos humanos. Sin embargo, este tipo de cláusulas corre el riesgo de quedar reducida a la condición de principio declarativo si no se las dota de mecanismos 
Vol.7, No 1. Diciembre de 2015 pp. $161-172$

adecuados que permitan monitorear la situación de los derechos humanos de las personas sometidas a la jurisdicción de las partes contratantes, o cuando no se prevén recursos sencillos, rápidos y efectivos ante un órgano previsto por el tratado que las ampare contra actos que violen sus derechos fundamentales. Por ello, se debe promover la articulación de un conjunto de normas a lo largo de todo el tratado para asegurar la primacía y plena efectividad de los derechos humanos y los principios democráticos durante la implementación del tratado. Para ello, se requiere que la Cláusula Democrática opere no como un artículo único, sino como un sistema de normas articuladas en el conjunto del tratado, de modo que se garantice la coherencia entre los objetivos comerciales y los principios de desarrollo, asociación y participación.

\section{REFERENCIAS.}

CELEMIN Rocio. (2012)TLC: El norte también existe. En: Publicación mensual. Revista CREDENCIAL. No. 214 (septiembre/2004). P. 22-28

COMITÉ DE REDACCIÓN. Los negocios del TLC. En: Publicación mensual, DINERO No. 194 (Nov 14, 2003). P. 28-117

COMITÉ DE REDACCIÓN. Los negocios del TLC. En: Publicación mensual, DINERO No. 194 (Nov 14, 2003). P. 28-117

SIERRA GARCIA, Jaime. Diccionario jurídico ajustado a la legislación colombiana, librería jurídica Sánchez Ltda. Tercera edición. 2001.

NARANJO MESA, Vladimiro. Teoría Constitucional e Instituciones Políticas. Novena Edición. Editorial Temis 2003.Bogotá.19 P 
CORTE CONSTITUCIONAL, Sala Plena. Bogotá, D.C., 24 de julio 2008. MP. Dr. Manuel José Cepeda Espinosa. 